\title{
Putting the Byte Into Career Development
}

\author{
Garry R. Walz \\ Jeanne Bleuer
}

Counselors, when discussing the use of computers in their work, will invariably turn to the question, "What do we need to know to be able to use computers effectively in career guidance and other areas of counseling?" The answers are almost as varied as the number of people discussing the quetion. At one extreme, there is a group of counselor computer users who fervently believe that programming skills using language such aS BASIC, LOGO, or PASCAL are essential for anything more than superficial use of computers in counseling. In their view, a little knowledge is a dangerous thing, and counselors who "play" at using computers in career counseling are likely to use them without the basic understanding and expertise they need to be thoughtful and discriminating users. At the other extreme are counselors who feel that the computer is simply a tool that can take some of the drudgery and routine out of counseling, thus making it possible for a counselor to focus on the building of relationships and the psychodynamics of a given person's situation. To them, using a computer is like driving a car--you don't need to know what's under the hood to turn on the engine and drive.

In our experience at ERIC/CAPS, we have come to believe that large numbers of counselors are in between these two

Garry R. Walz is Director and Jeanne Bleuer is Acting Associate Director, ERIC Counseling and Personnel Services Clearinghouse, The University of Michigan, Ann Arbor, MI. 
extremes. They have neither the time nor the inclination to become computer "hacks," but they also want to be more creative in their use of computers than simply turning them on and running a few programs. They see computers as a powerful new tool whose potentialities may well exceed those of any previous technology introduced into the counseling process. Therefore, they are willing to invest time and effort into the development of skills that will help them optimize their use of computers.

Based on our experience in working with counselors in numerous computer workshops and training sessions, we have identified several imperatives for counselors who are at this middle point in their professional encounters with computers. Webster defines an imperative as something "not to be avoided or evaded." While this definition may not apply to all ten statements for all counselors in all settings, we do feel that the issues raised are important enough to at least warrant consideration.

\section{TEN IMPERATIVES FOR COUNSELORS}

\section{Don't Expect Miracles}

If there is anything worse than a non-believer in a significant and promising innovation, it is a former believer who has been disillusioned by unrealized expectations and has become a confirmed cynic. The "I've tried it and it doesn't work" skeptic is immune to the usual forms of persuasion and logic.

As we prepare counselors to adopt and implement technological innovations like computers, we must immunize them against the fear and dejection that incapacitates them for future innovation and risk taking. We need to guard carefully against rambling rhetoric that promises perfection and dismisses doubts. We can help to prepare persistent and purposeful innovators in technology in career guidance if we present the picture of innovation as planful and sustained progress in areas previously resistant to improvement. Dramatic and mind-boggling changes are less likely to occur than a worthy improvement here and there. The immunized innovator has a "flashfore" for all that can go wrong and a mental preparation, if not a strategy, for responding if it does go wrong. It is through thoughtful and sustained adoption and adaptation that change and progress will occur. Perhaps it can be said that a career guidance innovator with modest expectations may experience immodest rewards. 


\section{Examine Software Carefully}

The career specialist has at least as difficult a task as the educator in selecting quality resources. Over the years, we have developed guidelines to help us in the process (e.g., never use a test which you yourself have not first taken and scored, judge the sources of a career brief, not only the typography, etc.). Software presents special problems because it is generally not as easily accessible for review and analysis as are print media. Skimming, checking references, determining the logic and flow, and checking out the presuppositions and underlying assumptions can be extremely difficult. The review is made all the more difficult by the lack of a tradition of intensive and extensive software review. The Educational Products Information Exchange (EPIE), journal and magazine reviews, and testimonials of other users can be helpful. But the sparse information presented is frequently not sufficient for the user to determine if it is appropriate for his/her particular use. In our experience, this has led some users to accept the availability of software for a particular brand of hardware as prima facie evidence of its quality (i.e., "If it runs on IBM XT, it has to be good"). Unfortunately, this shortcut to thorough review of a software can leave you very shortchanged. Some very poor programs can be run on some excellent computers!

At this time, the only really viable approach seems to be the user's personal inspection and review of the software. Lacking a real equivalent to the Buros Mental Measurement Yearbook, the user must make do with a patchwork of sources for determining what software to review. Print media reviews, personal testimonials of respected peers, and the feedback of organizations that regularly review software for their members are all likely, and sometimes good, sources for making an initial selection. Two new sources, software directories and electronic networks, offer additional information and evaluation on a more timely basis than the traditional sources.

Hardware considerations often have a way of dictating the software to be used. Sometimes this cannot be avoided. The ideal strategy, however, in selecting a computer-assisted career guidance system is first, to identify the desired uses; second, select the software program(s) that can accomplish these tasks; and third, purchase the hardware that is needed to run the software.

\section{Use Software Creatively.}

Counselors who choose to use computers to facilitate career guidance have several choices: (1) use an established system 
such as DISCOVER or SIGI; (2) select from a variety of commercially produced software that which is most relevant to a given need (e.g., a decision-making program for those having difficulty making career choices); (3) locate a non-commercial, public domain program by consulting a software directory (e.g., ERIC/CAPS Microcomputer Software for Counseling and Student Development); or (4) write their own program. Given so many options and choices available within each option, it would appear that the only problem would be one of choice--how to choose the best software program from among the many possibilities. Right? Wrong! In actuality, the choices are neither as clear-cut nor attractive as they may seem at first look. Many systems are expensive and require extensive use to justify; commercial software is often not as high quality as the packaging would suggest; public domain software, like many public items, is public because it's not good enough to be commercial; and who has the time (or expertise) to develop their own software? So what started as a plenitude of choices, after closer analysis, becomes a dearth of real resources. This unhappy state is enough to convince many would-be users of computers that individual counseling, while not without its drawbacks, is still the intervention of choice. "So much for technology," they say; "see me in another ten years when you really have something."

The dilemma of beginning users of computers in counseling is not unlike that of home users of personal computers. After the initial enthusiasm wears off, some persons express disappointment over how little real use they can make of them aside from word processing and game playing. In both the home and counseling use of computers, the problem is essentially the same--expectations and resourcefulness.

To make effective use of computers in counseling, counselors must avoid the unrealistic expectation that there is a program for career guidance that asks only to be plugged in. This approach to the use of computers suggests that the real task is selection--that once the choice is made, the hard work is over. In practice, just the opposite may prevail--the real work begins after the choice of a program. Seldom can you find the software that does precisely what you want it to and with the quality you need. Parts of a given program may be fine, but other parts may need to be selected from other software programs or even non-computerized resources. Having an appropriate expectation is the key--the career guidance delivery you need will not be handed to you in a box. What will provide you with what you need/want is your own creativity and resourcefulness in using what is available. By selecting parts of different software programs, by making the software part of a larger career guidance delivery system (with the software carrying 
responsibility for delivering only those aspects of the total program where it has real quality), and by using software that may have been developed for a different purpose than career guidance, you can develop a very powerful computer encompassing delivery system. Such a system does not have the ease of a "press any key" approach, but it does lead to very effective programs because of the creative and resourceful use of a wide variety of resources. It can give you coverage, variety, and utility that no single program is likely to present; and it has the big advantage that, by judicious selection from among existing software, you determine the message.

\section{Team with Your Client}

Many counselors, when first reflecting on how they may use computers in their career counseling, experience some trepidation about how the computer may negatively impact on the nature of their relationship with a client, even to the point where they fear that, for political or economic reasons, they may be replaced by computers. Computers, as the possessors of artificial intelligence and a memory far in excess of any of the mortals who will use them, assume an awesome and intimidating power.

Counselors who perceive computers as tools to be mutually and concurrently used by the counselor and the client recognize and appreciate what computers can contribute to counselor-client mutual learnings. By teaming with the client, the counselor can create a joint problem-solving climate in which, together, the counselor and client can strive to make the best use of the information the computer presents to them. They can focus on the accuracy and potential usefulness of the information and can identify and develop action strategies that are based on an integration of computer data and personal perception.

\section{Optimize Use of Client Data}

Occupational information, demographics, and test data about individuals are staples of career guidance. Knowledge of the world of work and personal characteristics is essential to making informed career plans and decisions. The overwhelming amount of information, and the difficulties involved in storing it in a way that it can be retrieved when you want it, have led many career specialists to take an anti-information stance. This leaves clients to fend for themselves for occupational or personal information.

However undesirable this approach may be for clients, it is understandable from the perspective of counselor/career specialists who want to spend time talking with clients, not 
shifting and sorting paper and data. The advent of the computer can dramatically change all this. By using spreadsheets and file management systems, career specialists can, with little or no additional day-to-day work, store and selectively retrieve information that enhances their ability to work with clients. Immediate access to data can be quite valuable in helping clients review their present circumstances, develop appropriate plans, and make informed decisions. Being able to go over relevant information with clients "on the spot" and to consider questions and implications regarding the data causes a subtle change to occur in how data and information are viewed and used. With the counselor and the client viewing the terminal together and determining what information they want presented, the two become a team working together to explore different courses of action. Information is not something relegated to use outside of the interview but an important, meaningful part of the interaction and mutual planning.

Another extremely helpful use is to be able to selectively retrieve and develop rosters of clients who possess certain traits or characteristics in common (e.g., interest in a particular career area, good or poor academic record, unusual or special skills, etc.). Using an appropriate file management program, counselors can create a variety of rosters and lists which are useful in working with each individual as well as presenting information about different groups of clients for reports, staff meetings, and presentations.

As counselors improve their ability to store and retrieve data through the use of specialized software programs, they need not fear being overwhelmed or usurped by the sheer quantity of information. The data become a useful resource under the counselor's control, to be used when and how they best serve counselor-client needs. Viewed as a useful resource, information becomes a means for improving planning and decision-making, rather than being a drag on them.

\section{Capitalize on Research Capabilities}

There are not many career specialists or counselors who see their role as one including research. While some refrain from research out of lack of interest, others do so because of a belief that the demands of conducting research or evaluation exceed their available time to do it, or require an expertise which they feel they lack. The use of computers in counseling will do nothing to change any of these conditions dramatically. Those who are disinclined to do research or are looking for reasons not to do it will always be able to justify their inaction. The computer, however, does inherently offer some opportunities for research which could make the difference for 
some counselors as to whether they do research or not. The capability of the computer to record type and frequency of use, as well as more complex attitudinal and outcome measures, can be a powerful stimulus to doing research.

There are a number of ways that computers can be used--ranging from basic counting functions to more complex analyses that can be helpful to counselors in improving the delivery of their service and in assisting decision-makers in evaluating the cost benefit of using computers in career guidance.

Perhaps one of the most basic ways that computers can assist the research process is in the building of databases--a running record of who used what program for what purpose and with what kind of outcomes, performance, or satisfaction. Information of this type, collected on a systematic basis, provides the data which are essential to effective research and evaluation. Some of the questions that are of interest include, "Who uses the computer, and for how long (on the average)?" "What are the favorite software programs?" "Are comparatively few people using it frequently, or is the use spread over a large number of people?"

Another focus would be devoted to outcomes. "How satisfied are the users with the experience?" "What changes have they experienced as a result of completing a particular software program?" "What did they not receive that they would like to have received?" are just examples of the directions that research could take. The use of innovative measurement techniques--such as retrospective pretesting where subjects recall and describe their pretreatment state after completing a treatment, and goal attainment scaling where subjects predict the worst possible, best possible, and the expected outcome of an experience--can provide a means for counselors and decision-makers to better understand the type and amount of contribution that computers have made to client changes.

One of the unique attributes of the computer for doing research is that it provides a common stimulus or input unlike the highly variable nature of individual or group counseling. With all users of a given software program receiving either the same program experience or purposefully planned variants of it, it is easier to examine the contribution of the program to client change or to look at the interaction between client need and program content. The computer influence on client change can be investigated either by asking clients to complete standardized questionnaires at the end of a computer program or by building into the computer program itself a series of diagnostic and assessment devices. Both approaches have their 
advantages, but either can provide useful results.

This cursory discussion of the potentialities of computers for contributing to research on counseling and career guidance is only illustrative of the many available options in doing research and evaluation. Suffice it to say that doing something in the way of research is likely to improve the quality of the service provided to clients and contribute to more informed decisions by administrators about the career guidance program.

\section{Intermix Computers with Other Counseling Interventions}

There is an implicit assumption, even a conviction on the part of many, that using computers in counseling and guidance means replacing counselors and/or counseling with computer inputs. From this perspective, using computers in career guidance is really substituting computers for human interaction. In actuality, even the most comprehensive of the computer-assisted career guidance systems never intended to do away with human intervention. They are designed to do just what their name implies, assist in the process.

Both research and experience would suggest that the most appropriate role for computers is to serve as one component of a system where they accomplish many important functions, but not all (or even the most important) of those required for a comprehensive experience. It is not the computer or "live" counselor, per se, that should be the basis for making decisions as to what component is responsible for carrying out specific functions. Some excellent software programs provide a very high level of interaction and could either supplement or be the primary source for covering an area such as values clarification. The decision in each case is an independent one determined by a number of factors, such as availability of resources, skill level of counselors, knowledge and skill of the typical user, etc. While the admixture of computer programs, counselors, and career guidance resources may vary in degree in different areas, the goal is always the same--to utilize the respective strengths of each component in order to maximize the overall quality of the total experience. In many situations, this means deciding how to use a component, rather than whether to use it or not. In research by Marin (1984), individual counseling contributed significantly to the ability of adults to use and apply information and insights gained from experiencing a computer-assisted career guidance program (DISCOVER). In this journal issue, Pyle has provided compelling illustrations of how group counseling can be combined with computer-assisted career guidance with favorable results on the interest and motivation, as well as the learning, of the participants. 
Knowing the quality of the different components and being able to blend them together into a significant learning experience for the user is a major challenge for the counselor developing the program.

"Computer enhanced counseling" is a description given by Walz (1984a) to an approach that focuses upon improving counseling by the judicious and creative use of different levels of computer contributions and counselor interventions. Adopting and adapting a wide range of software to reach pre-determined goals is advocated, along with the use of a formal computer-assisted career guidance program and individual and group counseling.

\section{Create Interactive Electronic Networks}

For most professions, the half-life of a professional person's knowledge--the time when half or more of his/her professional knowledge/skills are no longer relevant--is now only three to four years. Unless persons systematically renew their knowledge and skills, they are likely to experience a serious erosion in the performance of their work. Traditionally, persons have looked to professional journals, workshops, and conventions as means for renewal. As useful as these means are, they typically lack specificity and appropriate timing. You may have to wait quite some time for a conference or journal to appear that provides the information you need on a specific topic or problem. With the rapid changes occurring in the world of work and the introduction of new methods and resources in career guidance, counselors can be hard-pressed to be able to acquire and use the emerging knowledge which is essential to the effective performance of their work.

ERIC/CAPS has responded to this need by the creation of an interactive, electronic network for counselors. Through the use of telecommunications (TELENET, TYMNET, etc.) and a computer, the network, CAPS:HITECH, offers participants the double advantage of communicating with each other regardless of either place or time. No matter where the users are or when they want to send/receive messages, they can sign on for instant conversation and discussion.

CAPS:HITECH participants may enter items or questions for general discussion, respond to items already entered, send and respond to private messages, and request on-line consultation. In addition, on a regular basis ERIC/CAPS will introduce experts on topics of interest to the group and suggest special resources from ERIC which are relevant to the discussion(s) of the participants. 
The CAPS:HITECH network is a state-of-the-art technology for improving the quantity and the quality of communication among counselors on critical issues and important developments and resources which vitally affect their ability to provide effective career guidance. It is a technological medium for assisting counselors to master the demands and challenges of technology in an information society.

\section{Design Your Own Training Program}

"What is the best way to prepare counselors to use computers?" is a frequent question heard in counselor circles. The options are many and there are few definitive answers. Few, indeed, are the counselors using computers who will not offer personal testimonials on how they acquired "expertise" or what their prescriptions are for preparing counselors to be computer competent. Johnson and Sampson, in this journal issue, provide a comprehensive statement regarding the issues and approaches now extant.

In the most basic terms, we believe that there are four ingredients in a desirable counselor computer-competency training program. The first ingredient is a basic course in computer fundamentals with the emphasis on use. Such courses are readily available through colleges, business schools, adult education programs, and computer vendors. A key ingredient is that a computer lab be available which offers ample hands-on time with a computer. A second ingredient is attendance at a workshop on computers and counseling where the participants have the opportunity to learn about new developments in computers and can experience the new software that is relevant to counseling. Touching shoulders with more experienced users of computers and hearing their suggestions on using computers in counseling can also be very beneficial. ERIC/CAPS Annual Hi Tech Workshop is an example of a workshop that has grown in importance and utility over the years and can significantly contribute to a counselor's computer education. Unrestricted and uninhibited playfulness with a computer, such as occurs when a person has access to a computer in the privacy of a home or office, is the third ingredient. Everyone needs the opportunity to become familiar with a computer by trying out different software and being free to experiment and proceed by trial and error without worrying about who is watching and judging. The fourth ingredient is a network of experienced and knowledgeable colleagues. Anyone who has used a computer can attest to the times they have had questions when no amount of reading of technical manuals or working it through alone would suffice. Sometimes someone in the immediate vicinity can be found who can answer basic operating questions about a particular brand of computer or software/programming problem; but, for more 
substantial questions involving the use of computers for a specific counseling-related task, a network of computer-using counselors, such as CAPS:HITECH, is indispensable. Lacking the stimulation and modeling of the creative use of computers, a counselor may settle for only the basic uses of computers such as word processing and personal filing systems. To exploit the nearly limitless use of computers in counseling, counselors need interaction with others who are adventuresome and stimulated by the challenge of new uses and applications of computers to counseling.

\section{Minimize Isolation}

Being the bearer of new ideas in a questioning, if not resistive, environment is the unenviable position in which many proponents of computers in counseling find themselves. There is much about computers that can generate resistance on the part of counselors. It requires new skills to be learned, and the early learning comes slowly. There are few immediate, dramatic improvements, and it can seriously threaten established ways of providing career guidance. Little wonder that after the initial enthusiasm, some counselors settle for a minimal level personal use of a computer (of the record keeping variety) and relegate significant program innovation to a wistful, distant look in the eye. Both research and experience support the notion that, when a counselor enters a system with ideas differing from those prevailing in the system, the counselor changes more in the direction of being like the system than does the system change in becoming like the counselor.

Those who promulgate new concepts and methods should perhaps feel guilty for sending us off to war where the odds favor the opposition. It hardly seems just to sound off about the grand changes computers will make in counseling and education to lonely soldiers who must guard their flanks from attacks by frugal pot holders, conventional administrators, and skeptical colleagues.

If there is a maxi-strategy (with minimum effort and pretense) for introducing computers into a particular career guidance program, it is that we think of the entry as coming from a team or a network and never an individual. Even two persons with links to other like-minded individuals generate a force for change that helps to even up the odds. We need to devote at least as much time to preparing the would-be computer innovator for the innovator role as we do to preparing the would-be user of the innovation. 
It is probably too early to state in definitive terms precisely what the role of computers in counseling should be and how career counselors should be prepared to use them. The issues discussed in this paper do seem to be imperatives-considerations not to be avoided or evaded--for career counselors who wish to prepare themselves to use computers in their career guidance. With time, and particularly more exploration and experimentation, clearer images of what we can do with computers in career guidance and how we can prepare counselors to do it will emerge. For now, it is essential that we build a body of imperatives that focus and direct our efforts as educators and practitioners. For years our behavior has been inspired by and directed toward meeting the ten commandments. As an eleventh commandment was added to the first ten to summarize their essential meaning, so too we believe there is an eleventh imperative--career counselors must explore innovative ways in which they can use computers to enhance counseling. To avoid the eleventh imperative will surely threaten not only our effectiveness but our continued viability as a profession. "The most important new role for counselors in the use of computers may well be a sense of creative risk-taking that encourages, stimulates, and models for clients a change in viewpoint regarding the counseling experience and how to use it" (Walz, 1984b).

\section{REFERENCES}

Marin, P. P. (1984). The differential effectiveness of computerbased career counseling intervention and decision making style on progress in career decision status. Unpublished doctoral dissertation, The University of Michigan, Ann Arbor.

Walz, G. R. (1984a). The computer: Counselor enhancement or eclipse? CAPS Capsule, 2, 2-4.

Walz, G. R. (1984b). Role of the counselor with computers. Journal of Counseling and Development, 63, 135-138. 